\title{
THE TESTABILITY OF PROMINENT HYPOTHESES ON ACCESS TO UNIVERSAL GRAMMAR IN ADULT SLA
}

\author{
Frenette Southwood, Stellenbosch University
}

\section{INTRODUCTION}

There is a growing awareness among linguists that second language acquisition (SLA) is a promising area of inquiry, due to the fact that an understanding of how SLA occurs may provide a useful perspective on the mental processes involved in language learning and language use in general, as well as on the nature of the language faculty (Epstein, Flynn and Martohardjono 1996:677-678; Flynn 1988:76). A central question in SLA research today concerns the extent to which adult second language (L2) learners have access to the innate linguistic principles that guide first language (L1) acquisition, i.e. to Universal Grammar (UG). As we shall see, there is no shortage of proposed answers to this question. ${ }^{1}$

Among the proposed answers to the question of the accessibility of UG in adult SLA, hypotheses $^{2}$ may be divided into six groups. The first group of hypotheses claims that L2 learners have full access to UG, as L1 learners have. The second group also claims that the L2 learner has full access to UG, but these hypotheses further claim that the L2 learner's L1 knowledge is the starting point for SLA. The third group claims that, although L2 learners have full access to UG in SLA, the transfer of L1 parameter settings to the L2 learners' interlanguage (IL) grammar (for the target language) is partial. According to the researchers in the fourth group, L2 learners have partial but direct access to UG. The fifth group of hypotheses claims that the L2 learner has partial and indirect access to UG and also that the L2 learner's L1 knowledge is the starting point for SLA. Researchers in the sixth group claim that L2 learners have no access to UG in SLA and that their L1 knowledge in its entirety is transferred to the L2 learners' IL grammar.

In this article, each of ten prominent hypotheses on SLA will be placed into one of these six groups. The testability ${ }^{3}$ of each hypothesis will be evaluated. This entails identifying the test 
implications derived from each hypothesis. It will also be stated what experimental evidence would falsify each hypothesis. The article will conclude with comments on the state of linguistic theories in the field of SLA.

Before commencing the discussion of the ten hypotheses, the meanings of the terms "testability" and "test implications" need to be clarified. A distinction is made between testability in theory and testability in practice. According to the philosopher Hemple (1966:30), a hypothesis is testable in theory if (i) precise test implications can be derived from the hypothesis; and (ii) it is possible to specify what experimental findings, should they be available, would indicate whether the test implications of the hypothesis are true or false. According to Popper (1969:36), however, testability is refutability. By this he means that refutability is a necessary condition for empirical status. A hypothesis that is confirmable but not refutable, is, according to Popper, not an empirical hypothesis. To accommodate Popper's view, Hemple's definition of testability must be amended to the following: A hypothesis is testable in theory if (i) precise test implications can be derived from the hypothesis; and (ii) it is possible to specify what experimental findings, should they be available, would indicate whether the test implications of the hypothesis are false.

According to Hemple (1966:30), a hypothesis is testable in practice if (i) precise test implications can be derived from the hypothesis; and (ii) experimental findings which would indicate whether the test implications of the hypothesis are true or false, are in fact available. In the present article, the actual availability of experimental findings will not be discussed.

One factor which, according to Popper, can adversely affect the testability of a hypothesis, is the non-explicit nature (or obscurity) of the hypothesis. If the content of the hypothesis is not stated clearly and precisely, then it is not possible to derive test implications from it. Where such obscurity is present, it will be mentioned in this article.

Let us now turn to the ten hypotheses on access to UG in SLA. 


\section{FULL ACCESS, NO TRANSFER}

\subsection{Epstein, Flynn and Martohardjono's (1996) Full Access Hypothesis}

On Epstein et al.'s (1996:707) view, adult L2 learners have full and direct ${ }^{4}$ access to all properties of UG. These properties include all parameter settings, functional categories and feature values (Dube 2000:234; White 2000:135), even those that are not instantiated in the learner's L1. The initial state of L1 and L2 acquisition are, therefore, the same.

\subsection{Testability in theory of Epstein et al.'s hypothesis}

Because precise test implications can be derived from Epstein et al.'s hypothesis, and because it is possible to specify what experimental findings would indicate whether the test implications of the hypothesis are false, Epstein et al.'s hypothesis is testable in theory. The precise test implications which can be derived from Epstein et al.'s hypothesis are as follows: ${ }^{5}$

(i) If both L1 learners and L2 learners have full access to UG, then L2 learners (like L1 learners) should achieve maximum success, i.e. reach native-speaker status, in their L2.

(ii) If both L1 learners and L2 learners have full access to UG, then L2 learners and L1 learners of the same language will pass through the same developmental stages while learning/acquiring that language.

(iii) If no transfer takes place from the L1 to the L2, then no L1 effects should be found in the developing L2 of L2 learners (i.e. every L2 learner of a specific L2 should follow the same developmental path as every other L2 learner of that language, regardless of the learners' mother-tongues).

The experimental findings, should they be available, that would indicate whether the test implications of Epstein et al.'s hypothesis are false, would be that

(i) adult L2 learners do not achieve native-speaker status in their L2, despite ample, naturalistic exposure to mother-tongue speakers of the L2 and despite high motivation to learn the L2. It should to be noted that determining whether L2 learners reach native-speaker status in their L2 is complicated. The reason for this is that one would 
have to test the L2 learners only once they have reached their end state of development, and it is not always clear when and whether an L2 learner has reached this stage. If it is found that an L2 learner has not reached native-speaker status in his/her L2, it could simply be said that the L2 learner has not yet reached his/her end state of SLA;

(ii) L2 learners from different L1 backgrounds follow different developmental paths when learning their L2; and

(iii) a parameter setting that is not instantiated in the L1 of the L2 learner and that is instantiated in the target L2, is not in fact instantiated in the learner's IL grammar, despite the fact that the relevant positive evidence is available in the input. If Epstein et al.'s hypothesis is correct, then L2 learners must be able to infer from input not containing any explicit evidence that a more restricted parameter setting is required in the L2 than in the L1. Only then can one say that L2 learners have access to all of the possible settings for that parameter (Schachter 1991:108). In theory, it should further be possible to determine whether the learners' IL grammar exhibits any structures or features that occur in the learners' L1, but not in the target L2 (i.e. whether L1 transfer took place or not). In practice, however, things are more complicated. As stated by White (2000:142), the successful learning of L2 properties by intermediate learners (such as those examined in the 1996 Epstein et al. study) is irrelevant to the issue of L1 transfer to L2; aspects of the L1 could initially have been transferred, but "lost" during subsequent stages of SLA. Therefore, one would have to examine the L2 learners' IL grammars immediately after the onset of SLA. One can, however, never be sure that the first data obtained are really representative of the initial stage of SLA, as there might be a silent period before first production, and grammatical acquisition might take place during this silent period (White 2000:140). In practice, it is, therefore, not possible to be sure what one is testing. One has no guarantee that L2 learners tested for L1 effects at their initial stage of L2 production, are in fact at their initial stage of SLA. If learners are tested at a later stage, the L1 effects might have vanished during earlier stages of SLA. For this reason, the initial state claim made by Epstein et al.'s hypothesis is testable in theory, but not testable in practice. 


\section{FULL ACCESS, FULL TRANSFER}

Like Epstein et al., the second group of researchers claims that L2 learners, like L1 learners, have full access to UG. However, this group further claims that aspects of the L1 are transferred to the L2 at the onset of SLA.

\subsection{White (1988)}

\subsubsection{White's Parameter Resetting Hypothesis}

According to White (1988), both L1 learners and L2 learners have direct access to UG. During SLA, L2 learners start out with parameters set to their L1 values. This entails that full transfer takes place from the L1 to the L2. However, these transferred L1 parameter values merely constitute the initial state of SLA, and are by no means the sum of the aspects of UG to which the L2 learners have access. On White's view, L2 learners have full access to UG.

Where parameter values of the L1 and the L2 differ, parameter resetting ${ }^{6}$ needs to take place during SLA. This resetting will take place if the input to which the L2 learner is exposed contains the relevant positive evidence, ${ }^{7}$ i.e. evidence that the target L2 instantiates a parameter value that differs from the value instantiated in the learner's L1. Where positive evidence is not sufficient ${ }^{8}$ to bring about the desired change from the L1 parameter value to the correct L2 parameter value, this change has to be brought about through exposure to negative evidence, viz. exposure to direct evidence in the form of corrective feedback or explicit instruction ${ }^{9}$.

\subsubsection{Testability in theory of White's hypothesis}

The following precise test implications can be derived from White's hypothesis.

(i) If the L1 parameter settings form the starting point for (or the initial state of) SLA, then the initial L2 grammaticality judgements of L2 learners should reflect their L1 grammaticality judgements.

(ii) If L2 learners have full access to UG, then parameter resetting (and not mere memorisation of surface structures) should occur after exposure to negative evidence. 
(Instead of merely learning the correct surface forms, some change should take place in the learner's IL grammar.)

It is possible to specify what experimental findings, should they be available, would indicate whether the test implications of White's hypothesis are false. These findings would be that

(i) the initial L2 grammaticality judgements of L2 learners do not reflect their L1 grammaticality judgements. It is possible to determine whether these initial L2 grammaticality judgements reflect the L1 judgements of L2 learners or not. When gathering empirical data to evaluate this, subjects need to be selected with care, ensuring that they are really at the initial stage of SLA. ${ }^{10}$ If subjects are not selected according to strict criteria, and it is found that their initial L2 judgements do not reflect their L1 judgements, then it could be claimed that these subjects have merely passed the very early stages of SLA. This hypothesis would then not be testable, and, therefore, unfalsifiable; and

(ii) evidence of actual parameter resetting does not occur after exposure to negative evidence. The question regarding parameter resetting versus memorisation of surface structures can be tested by looking for evidence of so-called "clustering of properties". For example, Waher (1984:141-143) mentions that so-called "PRO-drop" languages have the following characteristics (or cluster of properties):

(a) a phonologically empty subject position;

(b) free inversion in simple sentences;

(c) "long WH-movement" of the subject, appearing to violate the Empty Category Principle; and

(d) empty resumptive pronominals in embedded sentences.

If an L1 speaker of a non-PRO-drop language (such as English) learns a PRO-drop language (such as Spanish) as L2, one would be able to determine whether the speaker has merely learned that subjects may be omitted in Spanish sentences or whether the speaker has reset the parameter from [-null subject] to [+null subject] by testing for the presence of the characteristics mentioned in (b) to (d) above. If the speaker omits subjects but his/her L2 does not, for example, show free inversion in simple sentences, parameter resetting has most probably not taken place. 
The question of whether parameter resetting, rather than mere memorisation of surface structures, occurs after exposure to negative evidence cannot be tested by looking for certain errors and drawing conclusions such as the following: if errors occur, learning has taken place, but if errors do not occur, parameter resetting has taken place. This is because production errors can still occur even though parameter settings have been changed (i.e. even though the learner's competence has changed), because performance is not always an accurate reflection of competence.

Because precise test implications can be derived from White.'s hypothesis, and because it is possible to specify what experimental findings, should they be available, would indicate whether the test implications of the hypothesis are false, the hypothesis is testable in theory.

\subsection{Schwartz and Sprouse (1994)}

\subsubsection{Schwartz and Sprouse's hypothesis}

Like White (1988), Schwartz and Sprouse (1994:319) propose a strong view of transfer. They claim that the L1 parameter values, among other things, serve as part of the initial state of SLA. ${ }^{11}$

From this point of departure of SLA (i.e. with L1 knowledge being the initial state of SLA), parameter values need to be revised and reset where the L1 and L2 values differ. According to Schwartz and Sprouse (1994:319), this revision (and perhaps re-revision), or this change in IL values, is possible in theory and occurs gradually as primary linguistic data (PLD) ${ }^{12}$ are accommodated by the developing IL grammar.

Possibly, not all parameters are revisable on the basis of PLD alone (Schwartz and Sprouse 1994:319). Therefore, many L2 learners never reach native-like competence in their L2. Herein lies the difference between the proposal of White (1998) and that of Schwartz and Sprouse. Contrary to White (1998), Schwartz and Sprouse do not believe it possible for parameters to be reset on the basis of exposure to negative evidence. According to Schwartz (1993:156-158), parameters can only be reset during SLA on the basis of exposure to positive evidence. Exposure to negative evidence in the form of explicit instruction or corrective 
feedback leads to learning about language. The L2 learner may, thus, learn the correct surface form that a structure would have, had the parameter been reset, without actual parameter resetting having taken place.

Where revision and resetting of parameters do take place, such revision and resetting conform at all times to UG principles, making the overall process of L1 acquisition and SLA very similar. To summarise their view, Schwartz and Sprouse (1994:316) state that each successive stage in the L2 learner's IL development emerges on the basis of interaction between the L1 grammar, positive evidence (from the PLD), UG principles and aspects of a (language) learning procedure.

\subsubsection{Testability in theory of Schwartz and Sprouse's hypothesis}

Precise test implications can be derived from Schwartz and Sprouse's hypothesis, and it is possible to specify what experimental findings would indicate whether the test implications of the hypothesis are false. Therefore, the hypothesis is testable in theory.

The first test implication is the same as the first for White's hypothesis, but the second implication differs from the second one for White's hypothesis. While White (1998) has to prove that parameter resetting (and not mere memorisation of surface structures) occurs after exposure to negative evidence, Schwartz and Sprouse need to prove the opposite, namely that mere learning of correct forms takes place and not changes in the 12 learner's IL grammar. Using Schwartz's (1993) terminology, the test implication can be stated as follows: If parameter resetting cannot result from exposure to negative data (Schwartz's term for negative evidence), then learned linguistic knowledge should be gained through exposure to negative data.

The first experimental finding, should it be available, that would indicate whether the test implications of Schwartz and Sprouse's hypothesis are false, would be similar to the first finding mentioned for White's hypothesis. However, the second experimental finding differs from the second one for White. As for testing the parameter-resetting-not-learning hypothesis of White (1998), one would have to look for evidence of clustering of properties. What would falsify Schwartz and Sprouse's hypothesis, is evidence of actual parameter resetting (and not 
learning) that is found after exposure to negative evidence. If clustering of properties occurs, parameter resetting (probably) took place. If clustering does not occur, one cannot be sure whether parameter resetting or learning has taken place. Again, it is not possible to say that learning took place if errors occur, because performance based on changed parameters (i.e. on changes in competence) may well contain errors.

\section{FULL ACCESS, PARTIAL TRANSFER}

\subsection{Vainikka and Young-Scholten (1994)}

\subsubsection{Vainikka and Young-Scholten's Minimal Trees Hypothesis}

The main difference between the hypothesis of Vainikka and Young-Scholten and that of Epstein et al., is that Vainikka and Young-Scholten claim that functional categories are absent in the earliest stages of SLA, while Epstein et al. claim that they are present. According to Vainikka and Young-Scholten's (1994:267-268) Minimal Trees Hypothesis, ${ }^{13}$ L2 learners have direct, but initially limited, access to UG in SLA. What is meant by "initially limited access" is that L2 learners start out with only lexical projections (hence "Minimal Trees"), transferred from the L1, and then acquire functional projections gradually on the basis of the L2 input and with the aid of UG. Like White, Vainikka and Young-Scholten claim that L2 learners start out with the L1 parameter values and then reset the parameters during SLA where necessary. ${ }^{14}$

\subsubsection{Testability in theory of Vainikka and Young-Scholten's hypothesis}

Because precise test implications can be derived from Vainikka and Young-Scholten's hypothesis, and because it is possible to specify what experimental finding would indicate whether the test implications of the hypothesis are false, their hypothesis is testable in theory. The precise test implications are as follows:

(i) If all L2 learners transfer only lexical projections, no transfer effects associated with functional projections should be present in the earliest stages of SLA.

(ii) Even if mature-state grammars show evidence of phonetically empty functional heads, ${ }^{15}$ L2 learners still transfer only lexical projections, and not lexical projections and functional projections with null phonetic content. 
The experimental finding, should it be available, that would indicate that the test implications of Schwartz and Sprouse's hypothesis are false, would be that functional projections are present in the very early stages of SLA. This would seem likely, should L2 learners, during the initial stages of SLA, be able to make consistent grammaticality judgements about any sentence that is made (un)grammatical by certain functional features.

Finding that the L2 learner's initial L2 production data contain only lexical projections, while not refuting the Minimal Trees Hypothesis, would also not prove it correct. The fact that functional categories are not present in the L2 learner's initial production data, does not prove that functional categories do not form a part of the L2 learner's initial mental representation of the L2. Absence of evidence is not evidence of absence (cf. White 2000:139). In other words, we are dealing here with the old problem in research on competence, namely that competence is not directly observable, only performance is, but performance is neither an accurate nor a complete reflection of competence.

If functional projections are found to be present in the L2 learner's IL grammar, then it could be said that only lexical projections were initially transferred and that functional projections were acquired later, i.e. that the learner is not really an initial-state L2 learner but more advanced. As was said when the testability of Epstein et al.'s theory was discussed, one cannot be certain that the first production data obtained from the L2 learner are really representative of the initial stage of SLA, as there might be a silent period before first production during which grammatical acquisition might take place (White 2000:140). A more reliable way of testing for the presence or absence of functional categories in the initial stage might thus be to use grammaticality judgement tasks and comprehension tasks, rather than relying on production data.

\subsection{Eubank (1993/4)}

\subsubsection{Eubank's hypothesis}

Eubank (1993/4:183-184) proposes the weak transfer view, in which lexical and functional projections, as well as the headedness of these projections, may transfer from the L1, but the morphology-driven feature values such as strength of inflection do not. In other words, certain 
parametric values (e.g. those associated with directionality) transfer from the L1 and form part of the initial state of the L2 learner's IL grammar, whereas other parametric values (e.g. those associated with inflectional strength, such as the so-called verb-raising parameter) do not transfer from the L1 and are initially unspecified in the IL grammar. Eubank also claims that whereas a strong feature leads to obligatory movement in the overt syntax and a weak features leads to prohibited movement in the overt syntax, an unspecified feature leads to optionality of overt movement (because it is neither weak nor strong).

This weak transfer view differs from that of Vainnika and Young-Scholten, who propose that none of the functional heads, or projections or feature values, are transferred from the L1 to the L2. On the weak transfer view, functional heads and their projections are transferred, but the feature values are not. Although only the functional heads and their projections are initially transferred to the L2, the L2 learner has full access to UG during SLA.

\subsubsection{Testability in practice of Eubank's hypothesis}

Two precise test implication can be derived from Eubank's hypothesis, but, because it is only possible to specify what experimental findings would indicate whether one of these implication is false, Eubank's hypothesis is only in part testable in theory. The precise test implications are as follows:

(i) If unspecified features lead to optionality of movement, no unspecified feature should exhibit consistently obligatory or consistently prohibited movement

(ii) If functional heads and their projections are transferred, but the features values are not, the parameters associated with inflectional strength should, in some way, be separate from the other parameters. Only then would it make sense, conceptually, that these inflectional strength parameters alone are not transferred from the L1 to the L2 together with the other parameters (Eubank 1993/4:201).

It is possible to specify what experimental findings, should they be available, would indicate whether the first test implication of Eubank's hypothesis is false. These findings would be that movement is neither consistently obligatory nor consistently prohibited (i.e. movement is not optional) in the initial stage of SLA. 
However, it is not possible to specify what experimental finding(s) would indicate that the second test implication is false. Finding that parameters associated with inflectional strength are not separate from the other parameters would not be damning to Eubank's proposal. This would merely require a detailed explanation from Eubank as to why only the inflectional strength parameters "remain behind" in the L1. If the inflectional strength parameters are found to be stored separately, then it is conceptually reasonable to say that they may act differently to the other parameters when it comes to transfer. Furthermore, if the inflectional strength parameters act differently to the other parameters when it comes to transfer, then it is conceptually reasonable to say that they may be stored separately. We are left here with the proverbial vicious circle.

\section{PARTIAL BUT DIRECT ACCESS}

\subsection{Krashen (1985)}

\subsubsection{Krashen's hypotheses}

Krashen's theory of SLA consists of five hypotheses (Krashen 1985:1). The content of each of these will be given briefly below.

(i) The Acquisition-Learning Hypothesis claims that there are two ways of developing ability in an L2, namely acquisition (which is a subconscious process of obtaining knowledge of language, identical to the process employed in L1 acquisition) and learning (which is a conscious process of obtaining knowledge about language, by focusing on form). These two types of knowledge are claimed to remain separate.

(ii) The Natural Order Hypothesis claims that the L2 learner acquires language rules in a predictable order, irrespective of the order in which the L2 learner is introduced to the rules in a language class.

(iii) The Monitor Hypothesis claims that learned knowledge acts as a monitor, editing the utterances produced by the acquired knowledge before (or sometimes after) the L2 learner speaks or writes.

(iv) The Input Hypothesis claims that an L2 learner needs comprehensible input, or $\mathrm{i}+1$, in order to acquire his/her L2, where $\mathrm{i}$ is the L2 learner's current level of competence and $\mathrm{i}+1$ is the next level along the natural order. 
(v) The Affective Filter Hypothesis claims that the L2 learner's affective filter, which is a mental block, can be up (such as when the learner is anxious or unmotivated), preventing input from reaching the L2 learner's Language Acquisition Device (LAD) ${ }^{16}$ or down (such as when the learner is not concerned with the possibility or consequences of failure), allowing input to reach the LAD and so allowing SLA to take place.

\subsubsection{Testability in theory of Krashen's hypotheses}

As was said in the introduction to this article, the non-explicit nature, or obscurity, of a hypothesis adversely affects the testability of that hypothesis. This is due to the fact that, if the content of the hypothesis is not clear and precise, then it is not possible to derive (precise) test implications from it.

Krashen's first hypothesis, viz. the Acquisition-Learning Hypothesis, is a hypothesis for which it is not possible derive test implications, because Krashen does not define "acquisition" and "learning" well enough for these concepts to be evaluated empirically. Furthermore, it is unclear what experimental findings, had one been able to derive test implications, would serve to confirm or refute this hypothesis. One could possibly attempt to determine when acquisition and when learning has taken place by testing for this as one would for White's parameter-resetting-vs-learning hypothesis, but Krashen himself does not refer to parameter resetting. Therefore, one would be using a criterion for acquisition (this criterion being parameter resetting) that Krashen himself does not acknowledge.

A precise test implication can be derived from Krashen's Natural Order Hypothesis. This implication can be stated as follows: If all L2 learners follow the same developmental route during SLA, L2 learners with different L1s learning the same L2 under different circumstances (via natural exposure to the L2, via classroom instruction, or via a combination of both) should learn the rules of their L2 in the same order. An experimental finding that would indicate that this test implication is false, would be evidence that different L2 learners follow different developmental routes (i.e. acquire the same grammatical structures in different orders). 
Test implications cannot be derived from Krashen's Monitor Hypothesis, because the content of this hypothesis is not precise. It is not clear how one would show that learned knowledge acts as a monitor for the utterances produced by the acquired knowledge. This lack of clarity stems, among other things, from the fact that "learning" and "acquisition", as well as the knowledge stemming from these two processes, are not well-defined. It is also not clear how one would prove that it is learned knowledge, and not some other mechanism, that does the monitoring.

Because "comprehensible input" has not been defined clearly by Krashen, it is not possible to derive precise test implications from the Comprehensible Input Hypothesis. Krashen does not state exactly what comprehensible input is and it is, therefore, unclear whether L2 learners in fact need it, as Krashen says they do. Furthermore, comprehensible input is supposed to lead the L2 learner to the next developmental level, but these levels have also not been defined. Therefore, it is not possible to determine whether comprehensible input does in fact lead to this next level.

Precise test implications can also not be derived from the Affective Filter Hypothesis, because it has not been clearly stated what this filter consists of. The factors or circumstances causing the filter to be up or down are also not described clearly. Although Krashen gives general descriptions of these factors or circumstances (e.g. Krashen (1985:3) states that the filter will be up when the learner "is unmotivated, lacking in self-confidence, or anxious ..., when he considers the language class to be a place where his weaknesses are revealed"), these factors and circumstances are merely examples and do not constitute an exhaustive list. If it had been possible to derive precise test implications, it would still not be clear what experimental finding(s) would refute this hypothesis. One reason for this is that it would not be possible to prove that the affective filter, and not some other mechanism, blocks the input from the LAD. A second reason is that it would not be possible to prove that a lack of acquisition can be blamed on input not reaching the LAD. The development and exact functioning of the affective filter will have to be described precisely before empirical research concerning the accuracy of Krashen's Affective Filter Hypothesis can be carried out. 
Because precise test implications cannot be derived from four of Krashen's five hypotheses, these four hypotheses are not testable in theory. ${ }^{17}$

\subsection{Felix (1985)}

\subsubsection{Felix's Competition Model}

According to Felix (1985:51), children younger than 13 years have full and direct access to

UG. They make use of a language-specific cognitive (LSC) system $^{18}$ to acquire language (both L1 and L2); they are not yet able to perform formal cognitive operations, such as general problem-solving, in order to acquire knowledge. At the age of about 13 years, Piaget's Stage IV (Formal Operations) has its onset. At this stage, it is possible for the L2 learner to make use of general problem-solving skills in SLA, using the general problem-solving cognitive (PSC) system. Both the LSC system and the PSC system can process language input, and, according to Felix, this is why competition arises between the LSC system (which is very effective for language acquisition) and the "stronger" or dominating, insuppressible PSC system (which is far less effective for language acquisition, as it is not languagespecific). UG is available to both the under-13 and over-13 L2 learner, but general problemsolving skills interfere with the over-13 L2 learner's access to UG, because of the competition between the LSC and the PSC.

\subsubsection{Testability in theory of Felix's hypothesis}

Felix's hypothesis is testable in theory, because precise test implications can be derived from it, and because it is possible to specify what experimental findings would indicate that the test implications of the hypothesis are false. The precise test implications which can be derived from Felix's hypothesis are as follows:

(i) If the LSC system and PSC system are in competition with one another, then L2 learners older than 13 years who have good problem-solving skills should be poor at learning their L2, and L2 learners who are successful at learning the L2 should have poor problem-solving skills.

(ii) If the PSC system develops at the age of 13, then children younger than 13 years of age should not be capable of performing any general problem-solving procedures. 
(iii) If low motivation and bad attitude can suppress the PSC system (as Bley-Vroman 1989:60 states they do), then L2 learners with poor attitude and low motivation should be the most successful L2 learners (Bley-Vroman 1989:61), because their PSC system is suppressed, leading to little competition with the LSC system.

(iv) If an L2 learner has access to two systems for processing language data, then the two systems should enter into direct competition instead of conspiring to make adults better L2 learners than children (White 1989:179).

It is possible to specify what experimental findings, should they be available, would indicate that the test implications of Felix's hypothesis are false. These experimental findings would be that

(i) L2 learners older than 13 years who have good problem-solving skills are also good at learning their L2, whereas L2 learners who are successful at learning the L2 have good problem-solving skills. It is possible to determine whether L2 learners with good problem-solving skills are poor at learning their L2 and vice versa. If this is not the case, it would mean that Felix's claim regarding the competition between the LSC system and PSC system is wrong;

(ii) children younger than 13 years of age are in fact capable of performing any general problem-solving procedures. If they are found to be capable of general problem solving procedures, Felix's hypothesis would be refuted, but if they are not, this does not necessarily provide support for Felix's hypothesis, because other factors may be relevant here;

(iii) that L2 learners with poor attitude and low motivation are the least successful L2 learners. Note, however, that it is difficult to test whether L2 learners with poor motivation and a bad attitude toward SLA are good at learning their L2 and vice versa. The reason for this difficulty lies in the definition of "motivation" and "attitude": these constructs have not yet been defined clearly enough to allow them to be subject to unambiguous empirical research; and

(iv) that, instead of entering into direct competition, the PSC system and the LSC system conspire to make adults better L2 learners than children. 
Felix states that the difference between adult and child L2 learners lies in the different learning strategies utilised by adults and children during SLA. He needs to prove that it is in fact a difference in learning strategy and not a difference in the availability or accessibility of UG. If the adult L2 learner no longer has (full) access to UG, then adults necessarily have to employ different language learning strategies than children do (children will use UG while adults cannot). What Felix needs to explain is why, if both adult L2 learners and child L2 learners have access to UG, these two age groups employ different learning strategies rather than both using UG that leads to successful SLA (Schachter 1991:111).

Felix's predictions are based on the assumption that children are more successful L2 learners than adults are. If this assumption is found to be true, then one cannot necessarily conclude that the reason for this is that UG is no longer available or no longer fully accessible to the adult L2 learner. It could also be, among other explanations, that proper triggering data are not available to the adult (Hilles 1991:307). It would also not be possible to determine whether children's success is due to different learning strategies in adults and children because of the unavailability of $\mathrm{UG}$, or simply due to different learning strategies in adults and children. It is clear how these two instances can be distinguished from one another empirically.

\section{PARTIAL BUT INDIRECT ACCESS, NO TRANSFER}

\subsection{Clahsen and Muysken (1989)}

\subsubsection{Clahsen and Muysken's hypothesis}

According to Clahsen and Muysken (1996:722), language learning involves a loss of information specified in UG. Initially, the L1 learner has access to all principles and parameters of $U G$, but once a certain parameter option has been chosen, the other option(s) are no longer accessible. This entails that once the learner's L1 grammar is mature, this speaker no longer has access to some aspects of UG.

Clahsen and Muysken (1989:23) claim that adult L2 learners have indirect access (via their L1) to stable UG principles, such as structure-dependency, that hold for every human 
language, but that they do not have access to UG parameters (i.e. to that set of options that have to be filled in by experience). Adult L2 learners, therefore, no longer have open or resettable parameters, only knowledge of UG as instantiated in their L1. SLA is, thus, language acquisition without access to parameter setting.

\subsubsection{Testability in theory of Clahsen and Muysken's hypothesis}

Precise test implications can be derived from Clahsen and Muysken's hypothesis, and it is possible to specify what experimental findings would indicate whether the test implications of the hypothesis are false. Therefore, the hypothesis is testable in theory. The precise test implications would be the following.

(i) If L2 learners have access only to those aspects of UG instantiated in their L1s, then the only structural properties of the target L2 that learners should know are those which are similar in their L1 and L2.

(ii) If parameter resetting does not take place during SLA, then there should be no evidence of parameter resetting, i.e. evidence of the L2 learner's IL grammar showing properties not found in the L1 (nor, for that matter, in the L2).

(iii) If adults acquire their L2 by employing (non-linguistic) cognitive systems, then one should occasionally find an adult L2 learner who draws incorrect conclusions about his/her L2 and, therefore, devises a grammar that is not constrained by UG.

One can specify what experimental findings, should they be available, would indicate that the test implications of Clahsen and Muysken's hypothesis are false. These findings would be that L2 learners, have more knowledge of the target L2 than what could have been gathered from their L1 or from the L2 input. This would be the case if parameter resetting takes place. As was explained previously, it is possible to test for parameter resetting. If one can show that this resetting does take place, Clahsen and Muysken's hypothesis would be refuted.

Note, however, that Clahsen and Muysken do not claim that L2 learners can never go beyond the properties of their L1 grammar in SLA. They claim that where L2 learners do seem to have gone beyond their L1 grammar, they have employed general learning skills, or nonlinguistic cognitive systems to do so. It has not yet been made clear what these systems are that L2 learners utilise. Before this is made clear, it will not be possible to clarify the 
distinction between parameter resetting on the one hand, and what looks like parameter resetting but is actually learnt by means of other non-UG systems.

It is also possible to test for so-called "wild" grammars, i.e. grammars that are not constrained by UG. If one finds such a grammar, then Clahsen and Muysken's hypothesis will, at least in part, be false. However, should one find no evidence of wild grammars, it would not necessarily prove Clahsen and Muysken's hypothesis correct.

\subsection{Schachter (1989)}

\subsubsection{Schachter's Window of Opportunity Hypothesis}

According to Schachter (1996:185), there is a period before which and a period after which a UG principle is not available to the language learner. In other words, Schachter proposes a sensitive period ${ }^{19}$ for parameter resetting: "for certain principles and parameters that depend on interaction with the environment, the principle or parameter will mature; ... [after the end of the sensitive period - FS] that parameter will no longer be available for fixing" (Schachter 1996: 185).

For SLA, Schachter (1989:75) proposes that all that remains of UG, is a language-specific instantiation, namely those principles and parameter settings that are instantiated in the L2 learner's L1 grammar. UG in its entirety will thus no longer be available as a knowledge source for the acquisition of an L2.

On this point, Schachter's proposal does not differ from Clahsen and Muysken's. Also, both Schachter and Clahsen and Muysken go on to say that L2 learners make use of a set of cognitive systems or cognitive mechanisms to learn their L2, although Clahsen and Muysken are non-specific about the nature of these mechanisms. Schachter states that these cognitive systems are not specifically designed for SLA. Schachter (1988:231) claims that the L2 learner controls these cognitive systems or mechanisms in that (s)he can decide when to discontinue their operation (the latter would happen when the L2 learner is satisfied with his/her communicative ability). These systems are not the only sources of information on the 
rules of the target L2 that the L2 learner can make use of during SLA; the L1 grammar and the L2 input data are also available as sources of information.

\subsubsection{Testability in theory of Schachter's hypothesis}

The specific test implications derived from Clahsen and Muysken's hypothesis can also be derived from Schachter's, and the same experimental evidence would falsify these implications. Two further implications, that could not be derived for Clahsen and Muysken's hypothesis, can be derived for Schachter's hypothesis, viz. the following.

(i) If there exists a sensitive period for parameter resetting, then certain parameters should only be resettable at certain times during SLA, and these "certain times" should be clearly preceded and clearly followed by a period in which no such resetting can take place.

(ii) If learners can in fact wilfully decide to terminate their own SLA, no further L2 learning should take place after an L2 learner has decided to cease learning.

According to Schachter, it is possible to specify which experimental evidence would falsify the first of these two test implications. In explaining how one can test for the existence of a sensitive period for parameter resetting, Schachter (1996:185) reviews a 1992 study by Lee. Lee studied Korean-speaking learners of American English who had the same length of exposure to the target L2 (3 years), but varying ages of first exposure to the target L2 (from 3 years to more than 22 years). The subjects were tested on their knowledge of the operation of Principle A of Binding theory in English, which includes knowledge of c-command and the Governing Category Parameter. It was found that adolescence (i.e. 11 to almost 14 years old) was the period in which most of the learners reset the Governing Category Parameter. The next most successful groups were the older children ( 8 to almost 11 years old) and the teenagers (14 to almost 18 years old). The least successful groups were the young children (6 to almost 8 years old) and the adults (19 to almost 26 years old). The results of Lee's study could be regarded as confirming the existence of a sensitive period for parameter resetting, i.e. a period before which and a period after which parameter resetting is less successful than in the sensitive period itself. This is one way in which Schachter's claim of a sensitive period for parameter resetting can be tested and possibly refuted. 
It is, however, not clear what experimental evidence would prove the second test implication false. The question is: How would one test whether L2 learners can willfully terminate their own SLA? One would presumably have to make use of self-examination questionnaires. It is, however, unlikely that an L2 learner would be able to determine consciously whether or not he/she has chosen to stop improving his/her L2 knowledge. It is, therefore, doubtful whether this test implication is falsifiable. Therefore, Schachter's hypothesis is not in its entirety testable in theory.

\section{NO ACCESS, FULL TRANSFER}

\subsection{Bley-Vroman's (1990) Fundamental Difference Hypothesis}

In brief, Bley-Vroman (1990) claims that UG itself is not accessible during SLA, ${ }^{20}$ but that a surrogate UG is accessible, through the L2 learner's knowledge of his/her L1. The L2 learner constructs this surrogate UG from his/her L1 knowledge (Bley-Vroman 1989:52). This indirect knowledge is accidental and incomplete (Bley-Vroman 1989:52) and serves as the explanation for the variable success that adult L2 learners exhibit in SLA.

According to Bley-Vroman's (1989:50) Fundamental Difference Hypothesis (FDH), the difference between L1 acquisition and SLA is

(i) internal, meaning that the difference is caused by differences in the cognitive state of adults and children, and not by external factors;

(ii) linguistic, meaning that the difference is caused by a change in the language faculty and not by some general change in learning ability; and

(iii) qualitative (and not just quantitative), meaning that the "domain-specific acquisition system" $^{21}$ (Bley-Vroman's term) is unavailable, not simply attenuated in SLA.

All children have full access to UG and use a domain-specific learning system to acquire their L1, which accounts for the fact that success is inevitable in child L1 acquisition. Adults, in contrast, no longer have access to $\mathrm{UG}$, but only to a mental representation of their L1 knowledge, and to a general abstract problem-solving system. 
According to Bley-Vroman (1996:718), the FDH "permits UG-like effects via the L1". In other words, the L2 learner does not have access to UG, but observes aspects of UG instantiated in his/her L1 (aspects such as structure dependency). The L2 learner expects certain things from the L2 because of his/her L1 knowledge; these expected things include a syntax, a lexicon, a phonological system with syllables, feet and phonological phrases, as well as the potential for an infinite number of sentences to be generated in the L2 (Bley-Vroman 1989:51). The L2 learner makes use of these "expectations", as well as various general cognitive mechanisms (not specifically linguistic, according to Bley-Vroman (1996:718)), in the construction of the L2. In this latter respect, Bley-Vroman agrees with Schachter.

Although Felix and Bley-Vroman both propose a general cognitive or general problemsolving system that adults (but not children) use for SLA, their proposals differ in at least one respect. Felix proposes that the problem-solving system is in competition with UG in adults, whereas Bley-Vroman proposes that the problem-solving system replaces UG in adults. BleyVroman's proposal also differs from that of Clahsen and Muysken and that of Schachter. Where the latter group of authors propose that L2 learners have access to those aspects of UG that are instantiated in their L1, Bley-Vroman proposes that they have no access to UG, but that they observe aspects of their L1 and then construct a surrogate UG.

\subsection{Testability in theory of Bley-Vroman's hypothesis}

It is possible to derive precise test implications from Bley-Vroman's hypothesis, and it is further possible to state which experimental evidence, if obtainable, would prove the hypothesis false. Therefore, Bley-Vroman's hypothesis is testable in theory. The precise test implications are as follows:

(i) If adult L2 learners employ general problem-solving skills to acquire their L2, then these learners should be totally unable to develop any knowledge about structural properties of the target language which cannot be directly induced from properties of surface structure.

(ii) If adult L2 learners have no access to UG, then parameter resetting should not take place during SLA. If parameter resetting does take place, it implies that the L2 learner has access to different parametric options that form part of the (inaccessible, according 
to Bley-Vroman) UG.

It is possible to specify what experimental findings, should they be available, would indicate that the test implications of Bley-Vromen's hypothesis are false. These experimental findings would be that

(i) no adult L2 learner draws the wrong conclusions about language or UG or the L2 and, on this basis, devises a "wild" grammar. As was said for Schachter's proposal, if adults acquire their L2 by observing "(not necessarily consciously) the most obvious largescale characteristics" (Bley-Vroman 1989:51-52) of their L1 and by employing nonlinguistic cognitive systems, then one should at least occasionally find an adult L2 learner who draws the wrong conclusions and, therefore, devises a grammar not constrained by UG; and

(ii) parameter resetting does occur. One can test for this, as explained previously. However, the question of how one can empirically distinguish between access to UG via the L1 and merely access to UG still arises ${ }^{22}$ (although this question is not of interest to Bley-Vroman who claims that there is no access to $\mathrm{UG}$, not even via the L1). In other words, how does the difference between these two present? Until we have a clear answer to this question, Bley-Vroman's Fundamental Difference Hypothesis will not be testable in practice.

Bley-Vroman has to explain why, if the L2 learner knows all these "expected" things (such as that the L2 has a syntax, a lexicon, and a phonological system with certain structures, as well as that an infinite number of sentences could be generated in the L2) about the target L2, the L2 learner is still not successful at SLA.

The question arises as to how one distinguishes UG-like effects via the L1 (proposed by BleyVroman) from UG effects via the L1 (proposed by an indirect access hypothesis). The "expectations" mentioned by Bley-Vroman seem almost indistinguishable from the "expectations" that are provided by (indirect) access to UG. If UG-via-L1 and UG then deliver the same surface data, then Bley-Vroman will have to explain why his account (the account resorting to a combination of strategies) should receive preference above the theoretically more simple UG account. 


\section{CONCLUSION}

In this article, a brief overview was given of prominent proponents of the various views on the accessibility of UG in adult SLA. One of the characteristics of a good theory is that it is testable (Mitchell and Myles 1998:5). Therefore, the testability in theory of each hypothesis was considered. It was found that some proposals were testable in theory whereas others were not, or at least not in their entirety. Whether testable (or falsifiable) in theory or not, all these hypotheses on the accessibility of UG in adult SLA continue to exist, together with a host of others not mentioned in this article.

White (1996:115) states that perhaps the time has come to stop asking the broad question of whether or not UG is available to L2 learners. According to her, this question has stimulated a great deal of fruitful research, but it is now the time for more detailed focus on the precise nature of the linguistic competence of language learners, a focus that will continue to draw on current linguistic theory.

Felix (1991:92) is of the opinion that the history of linguistic theory has taught us that fundamental issues are frequently not resolved by more and new data, but rather by careful examination of the rationale and conceptual perspective underlying opposing views. According to Felix, this holds true for the UG accessibility debate: discussions on methodological issues (on data collection and analysis, amongst others) often obscure rather than clarify the actual issues at stake.

I agree with neither White nor Felix. Although much research has been conducted on the availability of UG in SLA, one cannot necessarily call this research "fruitful", as it has provided no conclusive answers. We are still left with many hypotheses, some of which are unfalsifiable. According to Rosenberg (1986:343), a field can only be narrowed down to a smaller number of theories once a great deal of data have been collected. The evaluation and elimination of theories on the availability of UG in adult SLA can, therefore, only take place relatively late in the scientific process, once there are enough data. 
Therefore, contrary to what Felix claims, more data on the availability of UG in adult SLA are needed (especially as not all the existing data were obtained in empirically sound ways). Studies need to be duplicated, because not all studies examine that which they set out to examine, and existing research results need to be confirmed with similar findings.

Beretta (1991:497) states that, contrary to the already-successful sciences, where single theories tend to dominate, an (apparent) problem of multiple rival theories exists in SLA. SLA, as a young science, lacks an adequate, agreed-upon theory of language learning (Beretta 1991:493). Seeing that theory evaluation and subsequent theory elimination only take place after much data have been collected, I would propose that it is not time to move away from the question of the availability of UG in adult SLA. We only have rival theories that in many cases cannot be examined because no appropriate data exist. What is needed is more data collected in empirically sound ways, followed by the elimination of falsified theories. This will move us toward a single theory, or at least toward multiple complementary theories, rather than the current multiple rival theories, on the way in which adults learn an L2. 


\section{NOTES}

${ }^{1}$ According to Beretta (1991:495), Long stated in 1985 that there were 15 to 20 theories on SLA. Eight years later, Long (1993:225) stated that there were 40 to 60. According to Gregg (1996: 73), it would be more appropriate to call these "theories in SLA" because they are theories of production, or of variation, or of interaction, etc. Agreed, not all of these theories are/were on the accessibility of UG in SLA, but the figures are quoted here to provide an idea of the quantitative state of theory formation in SLA.

2 "Theories" is the term most frequently used in the literature. Long (1993: 225) states that "theories" (in inverted commas) may be preferred by some, as not all of these so-called "theories" are in fact theories: hypotheses, models, metaphors, frameworks and perspectives are all included in the list of things referred to as "theories". In this article, the term "hypotheses" will be used, because it is unusual to talk of the test implications of theories.

${ }^{3}$ Note that theories will not be critiqued on points other than testability and falsifiability, such as on the methodological soundness of the research offered as support for the theory.

4 "Direct" here means that the L2 learner does not access UG through those aspects of UG which are instantiated in the L1.

${ }^{5}$ For all these test implications, one assumes that all else is equal, i.e. that non-UG-related factors are excluded.

${ }^{6}$ When referring to a change in parameter setting, "resetting" is a problematic term. As Epstein et al. (1996:712) explain, the term could be seen as inaccurate because it implies that a parameter is reset from the L1 value to the L2 value, thereby losing the L1 value and no longer having that aspect of the L1 grammar represented in the language faculty. A more accurate term would be "new parameter setting" (Epstein et al. 1996:712) or "parameter setting", which would be the assignment of a new or different additional value to a parameter where the L1 parameter value differs from that of the L2. Despite its inaccuracy, "parameter resetting" is the popular and most widely used term in SLA writings, and for that reason it is used here.

${ }^{7}$ Positive evidence is evidence as to what is grammatical or possible in a language, whereas negative evidence is evidence as to what is ungrammatical of impossible in a language. 
${ }^{8}$ One instance of when positive evidence does not seem to be sufficient for bringing parameter resetting, involves that SLA of adverb placement in English by L1 speakers of French:

The Adjacency Condition on Case Assignment requires a case-receiving NP to be next to its case assigner. For this reason adverbs in English sentences may not occur between the (case-assigning) verb and the (case-receiving) NP, as illustrated in (1a):

1a. *Mary does slowly her homework

Apart from this restriction, adverb placement in English is "very free" (White 1989:151), as illustrated in sentences (1b) to (1e):

1b. Mary slowly does her homework

1c. Mary does her homework slowly

1d. Slowly Mary does her homework

1e. Mary is slowly doing her homework

In French, the equivalent of (1a), together with the other "English" adverb placement options, is acceptable, as illustrated in (2):

2. Marie fait lentement ses devoirs

Mary does slowly her homework

Therefore, it can be said that adjacency is not strictly observed in French (i.e. French is a [-strict adjacency] language), whereas adjacency is strictly observed in English (i.e. English is a [+strict adjacency] language).

For the L1 speaker of English learning French as an L2, sentences like (2) serve as positive evidence, i.e. as evidence that something that is not possible in their L1 is in fact possible in their L2.

The L1 speaker of French learning English as an L2 will not only need evidence of what is possible in English (i.e. positive evidence), but will also need negative evidence regarding adverb placement, i.e. evidence that sentences such as (1a) are impossible. Because of the very nature of impossible sentences, they do not occur in the input. The French L2 learner of English will only hear sentences such as (1b) to (1e), but because learners do not listen for non-occurring sentences or "gaps", this L2 learner will conclude that adverb 
placement in English is as free as it is in French and will, therefore, produce sentences such as (1a). This is one example of positive evidence being insufficient to bring about parameter resetting.

${ }^{9}$ Althouogh this was the position of White in 1998, see now (2002, personal communication) claims that L2 learners cannot make use of negative evidence to reset parameters. On White's current view, if the relevant positive evidence needed for parameter resetting is not available, then the parameter cannot be reset, even if negative evidence is provided.

${ }^{10}$ See the discussion on the testability of Epstein et al.'s hypothesis for a very brief discussion on the difficulty of determining the "real" initial stage of SLA.

${ }^{11}$ As White (2000:137) states, Schwartz and Sprouse claim that more than only the parameter values transfer. They believe that the entire grammar, apart from the lexical and morphological items and the phonetic matrices, constitutes the initial state of SLA.

${ }^{12}$ Schwartz (1993:148) states that PLD consist of contextualised utterances in the language environment of the learner. PLD provides the learner with positive evidence. Without exposure to PLD, language development will not take place.

${ }^{13}$ The Minimal Trees Hypothesis is in line with the so-called "Weak Continuity Approach" of L1 acquisition, according to which components of UG are available and accessible to children (i.e. L1 learners), but the functional categories need to be acquired on the basis of the input the child receives (Vainnika and Young-Scholten 1994:267).

${ }^{14}$ Note that under the Minimalist Programme (Chomsky 1995) most if not all parameters are linked to features and feature strengths of functional categories. Under this approach, Vainikka and Young-Scholten's hypothesis would actually predict that parameter resetting should never be necessary in SLA. The reason why it should not be necessary is that L2 learners do not start out with functional projections that are transferred from their L1; rather, they acquire these functional projections in the same way that an L1 learner would, namely on the basis of the input and with the aid of UG. Therefore, these L2 learners should actually be "spot-on" with parameter values for the L2 from the moment they have acquired functional projections.

${ }^{15}$ See Dube (2000: 237-238) for a brief summary of researchers who have argued for null functional elements.

16 "LAD" and "UG" are often used interchangeably, but, as Hilles (1991:306) warns, the two terms are, strictly speaking, not synonymous. The LAD is "a sort of UG plus", i.e. UG but 
also more than UG. It may include a regulatory mechanism which provides access to parameters, as well as a sort of algorithm which maps triggering data (viz. signals from the language learner's environment, necessary for a particular language system to develop) onto parameter values (Hilles 1991:306-307).

${ }^{17}$ The untestability of his hypotheses, however, has not caused Krashen to refrain from using them to draw pedagogical implications (Mitchell and Myles 1998:39).

${ }^{18}$ According to Bley-Vroman (1989:60), the LSC system is the LAD of other authors.

${ }^{19}$ See Schachter (1996:184-187) for a more comprehensive explanation of the Windows of Opportunity.

${ }^{20}$ According to White (2000:150), a genuine no access claim would be one that claims that interlanguages are constrained neither by the L1 nor by UG. White (2000:134), therefore, claims that the term "no access" is misleading when used to refer to Bley-Vroman's theory: "certain UG effects will, in fact, be manifested in interlanguage grammars, albeit weakly via the L1". However, having UG effects manifesting weakly via the L1 is not equal to, and does not imply, access to UG. As Bley-Vroman claims, observing the most obvious large-scale characteristics of their L1 and employing non-linguistic cognitive systems may lead to L2 learners having some conscious or unconscious knowledge of aspects of UG, but having this knowledge does not constitute having access to UG. Bley-Vroman's theory is, therefore, one of no access to UG.

${ }^{21}$ A definition, in the strict sense of the word, of "domain-specific learning system" is not provided, but it is said that this system includes the principles of UG. Bley-Vroman (1989:41) equates the domain-specific learning system with the LAD, and later (Bley-Vroman 1989:49) also calls it a "language acquisition system".

${ }^{22}$ See Felix (1991: 94-96) for an explanation of the difficulties of proving this. 


\section{REFERENCES}

Beretta, A. 1991. Theory construction in SLA: Complementarity and opposition. Studies in Second Language Acquisition 113: 493-511.

Bley-Vroman, R. 1989. What is the logical problem of foreign language learning? In S.M.

Gass and J. Schachter (eds.) Linguistic perspectives on second language acquisition.

Cambridge, New York and Melbourne: Cambridge University Press. pp. 41-68.

Bley-Vroman, R. 1990. The logical problem of foreign language learning. Linguistic Analysis 20: 3-49.

Bley-Vroman, R. 1996. What we have to explain in foreign language learning. Behavioral and Brain Sciences 19: 718.

Chomsky, N. 1995. The minimalist programme. Cambridge, Mass.: MIT Press.

Clahsen, H. and P. Muysken. 1989. The UG paradox in L2 acquisition. Second Language Research 5: 1-29.

Clahsen, H. and P. Muysken. 1996. How adult second language learning differs from child first language development. Behavioral and Brain Science 19: 721-723.

Dube, B. 2000. Where are the minimal trees? Evidence from early Zulu subordination. Second Language Research 16(3): 133-165.

Epstein, S.D., F. Flynn, and G. Martohardjono. 1996. Second language acquisition: Theoretical and experimental issues in contemporary research. Behavioral and Brain Sciences 19: 677-714.

Eubank, L. 1993/4. On the transfer of parametric values in L2 development. Language Acquisition 3(3): 183-208.

Felix, S.W. 1985. More evidence on competing cognitive systems. Second Language Research 1(1): 47-72.

Felix, S.W. 1991. The accessibility of Universal Grammar in second language acquisition. In L. Eubank (ed.) Point counterpoint: Universal Grammar in the second language. Amsterdam and Philadelphia: John Benjamins. pp. 89-103.

Flynn, S. 1988. Nature of development in L2 acquisition and implications for theories of language acquisition in general. In S. Flynn and W. O'Neil (eds.) Linguistic theory in second language acquisition. Dordrecht: Kluwer Academic Publishers. pp. 76-89. 
Gregg, K.R. 1996. The logical and developmental problems of second language acquisition. In W.C. Ritchie. and T.K. Bhatia (eds.) Handbook of second language acquisition. San Diego: Academic Press. pp. 50-81.

Hemple, C.G. 1966. Philosophy of natural science. Englewood Cliffs, N.J.: Prentice-Hall Inc. Hilles, S. 1991. Access to Universal Grammar in second language acquisition. In L. Eubank (ed.) Point counterpoint: Universal Grammar in the second language. Amsterdam and Philadelphia: John Benjamins. pp. 305-338.

Krashen, S.D. 1985. The Input Hypothesis: Issues and implications. London and New York: Longman.

Long, M.H. 1993. Assessment strategies for second language acquisition theories. Applied Linguistics 14(3): 225-249.

Mitchell, R. and F. Myles. 1998. Second language learning theories. London: Arnold.

Popper, K.R. 1969. Conjecture and refutations. The growth of scientific knowledge ( $\left.3^{\text {rd }} \mathrm{ed}\right)$. London: Routledge and Kegan Paul.

Rosenberg, A. 1986. Philosophy of science and the potentials for knowledge in the social sciences. In D.W. Fiske and R.A. Shweder (eds.) Metatheory in social sciences: Pluralisms and subjectivities. Chicago: University of Chicago Press. pp. 339-456.

Schachter, J. 1988. Second language acquisition and its relationship to Universal Grammar. Applied Linguistics 9(3): 219-235.

Schachter, J. 1989. Testing a proposed universal. In S.M. Gass and J. Schachter (eds.) Linguistic perspectives on second language acquisition. Cambridge, New York and Melbourne: Cambridge University Press. pp. 73-88.

Schachter, J. 1991. Issues in the accessibility debate: A reply to Felix. In L. Eubank (ed.) Point counterpoint: Universal Grammar in the second language. Amsterdam and Philadelphia: John Benjamins. pp. 105-116.

Schachter, J. 1996. Maturation and the issue of Universal Grammar in second language acquisition. In W.C. Ritchie and T.K. Bhatia (eds.) Handbook of second language acquisition. San Diego: Academic Press. pp. 159-193.

Schwartz, B. 1993. On explicit and negative data affecting competence and linguistic behavior. Studies in Second Language Acquisition 15: 147-163.

Schwartz, B.D. and R. Sprouse. 1994. Word order and nominative case in non-native language acquisition: A longitudinal study of (L1 Turkish) German interlanguage. In T. 
Hoekstra. and B. Schwartz (eds.) Language acquisition studies in generative grammar. Amsterdam and Philadelphia: John Benjamins. pp.317-368.

Vainnika, A. and Young-Scholten, M. 1994. Direct access to X'-theory: Evidence from Korean and Turkish adults learning German. In T. Hoekstra and B. Schwartz (eds.) Language acquisition studies in generative grammar. Amsterdam and Philadelphia: John Benjamins. pp. 265-316.

Waher, H. 1984. Chomsky se teorie van 'government-binding'. SPIL PLUS 9: 1-187.

White, L. 1988. Island effects in second language acquisition. In S. Flynn and W. O'Neil (eds.) Linguistic theory in second language acquisition. Dordrecht, Boston and London: Kluwer Academic Publishers. pp. 144-172.

White, L. 1989. Universal Grammar and second language acquisition. Amsterdam and Philadelphia: John Benjamins Publishing Company.

White, L. 1996. Universal Grammar and second language acquisition: Current trends and new directions. In W.C. Ritchie and T.K. Bhatia (eds.) Handbook of second language acquisition. San Diego: Academic Press. pp. 85-120.

White, L. 2000. Second language acquisition: From initial to final state. In J. Archibald (ed.) Second language acquisition and linguistic theory. Massachusetts and Oxford: Blackwell Publishers. pp. 130-155. 